\title{
ANALISIS KINERJA KEUANGAN PT. BANK CENTRAL ASIA TAHUN 2017-2019
}

\author{
Choirun Nisful Laili \\ choirunnisful@unhasy.ac.id \\ Universitas Hasyim Asy'ari
}

\begin{abstract}
ABSTRAK
Penelitian ini menguji tentang kinerja keuangan PT. Bank Central Asia, Tbk. selama tahun 2017 hingga 2019. Pengukuran kinerja keuangan ditinjau dari beberapa aspek, yaitu capital, earning, dan liquidity dengan indikator atau rasio keuangan yang digunakan adalah Capital Adequacy Ration (CAR) untuk mengukur aspek capital. Kemudian untuk aspek earning menggunakan Return on Asset (ROA) dan rasio Beban Operasional terhadap Pendapatan Operasional (BOPO). Dan untuk aspek liquidity menggunakan Cash Ratio (CR). Hasil penelitian ini menyatakan bahwa kinerja keuangan PT. Bank Central Asia, Tbk untuk tahun 2017 hingga 2019 dari sisi capital ratio, earning ratio dan liquidity ratio masuk dalam kriteria bank yang sehathasil dan hal tersebut sudah sesuai dengan peraturan SK DIR BI Nomor: 30/21/KEP/DER tanggal 30 April 1997 tentang Tata Cara Tingkat Kesehatan Bank.

Kata Kunci: kinerja keuangan, bank, capital ratio, earning ratio, liquidity ratio
\end{abstract}

\section{ABSTRACT}

This study examines the financial performance of PT. Bank Central Asia, Tbk. during 2017 to 2019. Measurement of financial performance in terms of several aspects, namely capital, earnings, and liquidity with the indicator or financial ratio used is the Capital Adequacy Ration (CAR) to measure aspects of capital. Then for the earning aspect using Return on Assets (ROA) and the ratio of Operating Expenses to Operating Income (BOPO). And for the liquidity aspect using the Cash Ratio (CR). The results of this study indicate that the financial performance of PT. Bank Central Asia, Tbk for 2017 to 2019 in terms of capital ratios, earning ratios and liquidity ratios are included in the criteria for a successful bank and this is in accordance with peraturan SK DIR BI Nomor: 30/21/KEP/DER tanggal 30 April 1997 concerning Bank Soundness Level Procedures.

Keywords: financial performance, bank, capital ratio, earning ratio, liquidity ratio

\section{PENDAHULUAN}

Industri keuangan menjadi salah satu industri yang krusial dalam suatu negara. Industri keuangan khususnya perbankan adalah industri yang dibutuhkan dalam aktivitas transaksi keuangan disemua lapisan masyarakat. Sebagai lembaga perantara, perbankan memiliki peran yang sangat penting dalam memenuhi kebutuhan modal kerja dan investasi pda sektor riil. Oleh karenanya, fungsi utama perbankan dalam 
infrastruktur kebijakan makroekonomi memang dalam konteks bagaimana uang meningkatkan nilai tambah ekonomi secara efektif (Chandra et al., 2016). Di Indonesia tersedia bank yang melayani kebutuhan masyarakat di bidang keuangan antara lain Bank Negara Indonesia (BNI), Bank Rakyat Indonesia (BRI), Bank Tabungan Negara (BTN), Bank Mandiri, Bank Bukopin, Bank Mega, Bank Central Asia (BCA). Dalam menjalankan kegiatan operasionalnya, perusahaan harus berorientasi pada pengembangan rencana bisnis yang baik agar tetap dapat memperoleh keuntungan dan survive. Rencana bisnis tidak dapat dipisahkan dari risiko dan uncertainty. Keuntungan akan diperoleh perusahaan yang baik kinerjanya. Dan yang perlu dipahami dalam perolehan keuntungan berkaitan dengan analisis kinerja keuangan. Evaluasi kinerja adalah analisis dan pengendalian data perusahaan. Kinerja perusahaan ditingkatkan di luar kegiatan bisnisnya agar dapat bersaing dengan perusahaan lain (Citra et al., 2013) Salah satu cara untuk menganalisis kinerja keuangan adalah dengan menganalisis laporan keuangan perusahaan yang terdiri dari neraca dan laporan laba rugi. Alat analisis yang sering digunakan untuk menentukan kinerja keuangan adalah rasio keuangan (Kurniawan, 2017). Dengan menganalisis laporan keuangan akan sangat membantu perusahaan untuk mengestimasi tingkat risiko yang dihadapi, uncertainty dan dapat berkontribusi menghasilkan perumusan rencana yang lebih baik.

Berdasarkan kapitalisasi pasar atau market capitalization berbagai perbankan yang ada di Indonesia, hanya ada beberapa perbankan yang memiliki market capitalization yang besar yakni diatas 100 triliyun. Data dari RTI application menunjukkan bahwa jika ditinjau dari market capitalization urutan pertama ditempati oleh Bank Central Asia (BCA) sebesar 828,41 triliyun, Bank Rakyat Indonesia (BRI) sebesar 587,13 triliyun, Bank Mandiri sebesar 305,67 triliyun, Bank Negara Indonesia (BNI) sebesar 111,89 triliyun.Berdasarkan data yang dirilis oleh Bloomberg, bank BCA menempati posisi kedua setelah DBS Bank dari Singapore sebagai bank dengan market capitalization tertinggi di Asia Tenggara (www.idnfinancial.com). Market capitalization atau kapitalisasi pasar memberikan informasi ukuran perusahaan berdasarkan pada nilai saham yang beredar dalam periode tertentu. Yusra, (2019) menyatakan bahwa pada umumnya saham yang kapitalisasinya besar menjadi incaran investor untuk berinvestasi jangka panjang karena potensi pertumbuhan perusahaan yang mengagumkan disamping pembagian dividen serta eksposur risiko yang relatif rendah. Potensi pertumbuhan 
perusahaan ini dapat diamati dari kinerja yang diberikan oleh perusahaan khususnya kinerja keuangan.

\section{METODE}

Metode Penelitian yang di gunakan adalah metode kuantitatif. Data dikumpulkan dengan metode dokumentasi dan studi pustaka.Data yang dipergunakan diakses melalui website www.idx.co.id sebagai website resmi Bursa Efek Indonesia.Jenis data yang digunakan adalah data sekunder dari PT. Bank Central Asia,Tbk yaitu data laporan keuangan dan laporan tahunan tahun 2017, 2018, dan tahun 2019.

Pengukuran dalam penelitian ini bersifat kuantitatif yang berfokus pada sisi capital, earning, dan liquidity. Analisis data dilakukan dengan menghitung rasio-raiso keuangan pada setiap aspek tersebut, dengan masing-masing perhitungan rasio sebagai berikut:

Tabel 1

Pengukuran Aspek Penilaian Kinerja Keuangan

\begin{tabular}{|c|c|c|}
\hline Rasio & Analisis & Rumus \\
\hline Rasio Capital & $\begin{array}{l}\text { a. Capital Adequacy Ratio (CAR) } \\
\text { b. Debt to Equity Ratio }\end{array}$ & $\begin{array}{c}\frac{\text { ModalSendiri }}{\text { ATMR }} \times 100 \% \\
\text { Sumber: Sujarweni (2017) } \\
\frac{\text { Total Hutang }}{\text { Total Equity }} \times 100 \% \\
\text { Sumber: Sujarweni (2017) }\end{array}$ \\
\hline Rasio Earning & a. Return on Asset (ROA) & $\begin{array}{l}\frac{\text { Laba Sebelum Pajak }}{\text { Total Aktiva }} \times 100 \% \\
\text { Sumber: Sujarweni (2017) }\end{array}$ \\
\hline & $\begin{array}{l}\text { b. Beban Operasional terhadap Pendapatan } \\
\text { Operasional }\end{array}$ & $\begin{array}{c}\frac{\text { Beban Pendapatan }}{\text { Pendapatan Operasional }} \times 100 \% \\
\text { Sumber: Sujarweni }(2017)\end{array}$ \\
\hline Rasio Liquidity & Cash Ratio & $\begin{array}{c}\frac{\text { Aktiva Lancar }}{\text { Hutang Lancar }} \times 100 \% \\
\text { Sumber: Sujarweni (2017) }\end{array}$ \\
\hline
\end{tabular}

Sumber : Data diolah, 2021.

\section{HASIL DAN PEMBAHASAN}

Bedasarkan laporan keuangan PT Bank Central Asia Tbk yang peneliti ' butuhkan sudah lengkap, tersaji dalam neraca dan laporan laba rugi (Annual Report) pada periode 2017 sampai dengan tahun 2019. Selanjutnya peneliti mengadakan analisis kuantitatif atau di sebut dengan analisis data statistik yang menggunakan analisis CAMEL yang terfokuskan Pada rasio Capital, earning dan liquidity untuk menilai kinerja keuangan PT. Bank Central Asia Tbk.

Aspek permodalan diukur dengan rasio Capital Adequacy Ratio (CAR). Rasio 
Permodalan diukur dengan membandingkan antara rasio modal terhadap aktiva tertimbang menurut risiko (ATMR), baik memperhitungkan resiko kredit dan pasar. Modal berasal dari modal inti ditambah dengan modal pelengkap. Sementara itu, Aset Tertimbang Menurut Risiko (ATMR) adalah jumlah aktivayang telah disertai bobot risiko masing-masing dan jumlahnya tergantung pada tingkat risiko inheren dari aset itu sendiri dan golongan nasabah, penjamin ataupun sifat agunan.

\section{Tabel 2}

Hasil PengukuranCapital Adequacy Ratio (CAR) (dalam jutaan rupiah)

\begin{tabular}{|c|c|c|c|c|}
\hline Tahun & Jumlah Modal & ATMR & Hasil (\%) & Kriteria \\
\hline 2017 & 264.511 .429 & 518.366 .130 & $51,02 \%$ & Sehat \\
\hline 2018 & 305.703 .352 & 597.771 .797 & $51,14 \%$ & Sehat \\
\hline 2019 & 348.991 .043 & 652.652 .229 & $55,78 \%$ & Sehat \\
\hline
\end{tabular}

Sumber : Data diolah, 2021

Berdasarkan tabel diatasdapat diketahui bahwa PT Bank Central Asia Tbk pada periode 2017-2019 cenderung mengalami peningkatan, peningkatan tertinggi terjadi pada tahun 2019 peningkatan sebesar 4.64\% di bandingkan pada tahun 2018 yang peningkatannya sebesar $0.12 \%$. Kinerja keuangan PT Bank Central Asia Tbk yang diukur dengan menggunkan rasio Capital Adequacy Ratio (CAR) termasuk dalam kriteria sehat dalam menutupi resiko-resiko kemungkinan yang terjadi pada perusahaan selama satu periode berjalan. Hasil tersebut sesuai dengan peraturan SK DIR BI Nomor: 30/21/KEP/DER tanggal 30 April 1997 tentang Tata Cara Tingkat Kesehatan Bank dalam menyediakan modal periode 2017-2019 meskipun mengalami fluktuatif yang masih menguntungkan.Penelitian ini sejalan dengan penelitian terdahulu yaitu menurut Manimpurung et al., (2014) pada jurnal Analisis Kinerja Keuangan dengan Menggunakan CAMEL pada PT Bank Rakyat Indonesia (Persero) Tbk periode 20092012, menyatakan bahwa PT Bank Rakyat Indonesia (Persero) Tbk tergolong perbankan yang berkategori sehat. Rasio Kecukupan Modal/ Capital Adequacy Ratio (CAR) tahun 2009-2012 juga terbukti memiliki modal yang cukup untuk menutupi semua risiko yang mungkin timbul dari investasi pada aset produktif yang berisiko, dan untuk membiayai investasi pada aset tetap dan inventaris. Kedua, menurut Satria \& Hatta, (2015) dalam penelitiannya yang melakukan penilaian kinerja keuangan 10 bank terkemuka di Indonesia dan salah satunya BCA, jika ditinjau dari rasio CAR menunjukkan hasil yang baik berarti dari segi permodalan BCA masuk dalam kategori baik. Ketiga, menurut 
Jeremiah (2013) pada jurnal Analisis Laporan Keuangan dengan Menggunakan Metode CAMEL untuk Menilai Tingkat Kesehatan Perbankan Bank Umum Milik Pemerintah periode 2010-2011 dikatakan bahwa dalam menghadapi gejolak ekonomi dan dampak negatif dari lingkungan eksternal bank, hasil kinerja keuangan bank cukup sehatdan mampu menghadapi gejolak ekonomi, akan tetapi manajemen seharusnya lebih fokus dalam memperbaiki tingkat kesehatan.

Aspek earning merupakan kemampuan perusahaan dalam menghasilkan laba dalam periode tertentu. Aspek earning diukur dengan dua rasio, yaitu return on assets ration (ROA) dan rasio beban operasional terhadap pendapatan operasional (BOPO). Dan berikut adalah hasil perhitungan earning ratio dengan return on asset sebagai indikator.

\section{Tabel 3}

Hasil Pengukuran Return on Asset (ROA) (dalam jutaan rupiah)

\begin{tabular}{|c|c|c|c|c|}
\hline Tahun & Laba Sebelum Pajak & Total Aktiva & Hasil $(\boldsymbol{\%})$ & Kriteria \\
\hline 2017 & 29.158 .743 & 750.319 .671 & $3,88 \%$ & Sehat \\
\hline 2018 & 32.706 .064 & 824.787 .944 & $3,96 \%$ & Sehat \\
\hline 2019 & 36.288 .998 & 918.989 .312 & $3,94 \%$ & Sehat \\
\hline
\end{tabular}

Sumber : Data diolah, 2021

Berdasarkan perhitungan Return On Asset (ROA) tabel 3 di atas dapat diketahui bahwa kinerja keuangan PT Bank Central Asia Tbk yang diukur dengan menggunkan rasio Return On Asset (ROA) masuk dalam kriteria sehat, hasil tersebut seiring dengan peraturan SK DIR BI Nomor: 30/21/KEP/DER tanggal 30 April 1997 tentang Tata Cara Tingkat Kesehatan Bank mengenai kemapuan memperolah laba, meskipun mengalami fluktuasi setiap tahunnya masih dalam standar ketentuan sehat yang telah di tetapkan.Penelitian ini sejalan dengan penelitian terdahulu yaitu pertama menurut (Widyanto, 2012), pada jurnal yang berjudul Analisis Tingkat Kesehatan dan Kinerja Keuangan Bank dengan menggunakan Metode CAMEL pada PT. Bank Mega Syariah Indonesia periode 2008-2010 untuk menyatakan bahwa hasil kesehatan dan kinerja keuangan dengan rasio Return On Asset (ROA) dalam kriteria sehat. Kedua, berdasarkan penelitian Wensen et al., (2017) yang menguji perbandingan kinerja keuangan Bank Central Asia dan Bank Mandiri periode tahun 2011-2015 menyatakan bahwa ditinjau dari rasio ROA Bank Central Asia memiliki kinerja yang baik. Ketiga, menurut Saleo, (2015) pada jurnal Analisis Tingkat Kesehatan Bank dengan 
menggunakan Metode CAMEL pada PT. Bank Mandiri Tbk periode 2011-2015 untuk menyatakan bahwa hasil kesehatan dan kinerja keuangan dengan rasio Return On Asset (ROA) dalam kriteria sehat. Ketiga menurut Kevin, (2013) berdasarkan hasil pengujian tingkat kesehatan dan financial performance dengan rasio Return On Asset (ROA) menunjukkan bahwa Bank Umum Pemerintah terbukti masuk dalam kriteria sehat.

Kemudian aspek earning dalam penelitian ini juga diukur dengan rasio Beban Operasional Terhadap Pendapatan Operasional (BOPO). Rasio BOPO diimplemensikan guna mengukur tingkat efisiensi dan kemampuan bank dalam menjalankan kegiatan operasinya.

\section{Tabel 4}

Hasil Pengukuran Biaya Operasional Terhadap Pendapatan Operasional (BOPO) (dalam jutaan rupiah)

\begin{tabular}{|c|c|c|c|c|}
\hline Tahun & Beban Operasional & $\begin{array}{c}\text { Pendapatan } \\
\text { Operasional }\end{array}$ & Hasil (\%) & Kriteria \\
\hline 2017 & 30.648 .222 & 59.073 .928 & $51,88 \%$ & Sehat \\
\hline 2018 & 33.393 .140 & 66.099 .168 & $50,51 \%$ & Sehat \\
\hline 2019 & 39.025 .521 & 75.314 .519 & $51,81 \%$ & Sehat \\
\hline
\end{tabular}

Sumber : Data diolah, 2021

Berdasarkan hasil perhitungan rasio BOPO ditarik kesimpulan bahwa kinerja keuangan yang diukur menggunakan rasio BOPOtermasuk dalam kriteria sehat dalam menutupi risiko-risiko kemungkinan yang terjadi pada PT Bank Central Asia Tbk selama satu periode berjalan. Hasil tersebut sudah sesuai dengan peraturan SK DIR BI Nomor: 30/21/KEP/DER tanggal 30 April 1997 tentang Tata Cara Tingkat Kesehatan Bank dalam menyediakan modal periode 2017-2019 meskipun mengalami fluktutif yang masih menguntungkan. Beban operasional yang ditanamkan pada pendapatan operasional mampu menghasilkan laba perusahaan yang cukup besar. Kondisi ini terjadi karena beban operasional mengalami penurunan disetiap tahunnya dan pendapatan operasional lebih besar dari beban operasional yang setiap tahun mengalami peningkatan dan penurunan.Penelitian ini sejalan dengan penelitian terdahulu yaitu pertama menurut Riandi (2016), pada jurnal Analisis kinerja keuangan PT Bank Syariah Mandiri dan PT Bank Mandiri Tbk dengan menggunakan Metode CAMEL pada periode 2010-2014 menyatakan bahwa PT Bank Syariah Mandiri dan PT Bank Mandiri Tbk menggunakan rasio Earning dengan analisis Beban Operasional Terhadap Pendapatan Operasional (BOPO) dalam kriteria sehat. Kedua, berdasarkan penelitian (Wensen et al., 
2017) yang menilai perbandingan kinerja keuangan Bank Central Asia dan Bank Mandiri periode tahun 2011-2015 menyatakan bahwa ditinjau dari rasio BOPO Bank Central Asia sudah cukup efisien. Ketiga, menurut Rika (2017) yang juga menganalisistingkat kesehatan bank dengan menggunakan PT. Bank Mandiri Tbk menggunakan rasio earning dengan analisis BOPOtermasuk dalam kriteria sehat. Ketiga, menurut Widyanto, (2012) pada jurnal Analisis Tingkat Kesehatan dan Kinerja Keuangan Bank dengan menggunakan Metode CAMEL pada PT. Bank Mega Syariah Indonesia periode 2008-2010 menggunakan rasio Earning dan analisis BOPOjuga menyebutkan dalam kriteria sehat.

Aspek likuiditas kali ini diproksikan dengan menggunakan cash ratio. Rasio ini menggambarkan kemampuan suatu bank untuk membayar kembali hutang dangan perhitungan aktiva lancar terhadap hutang lancar atau kewajiban pada jangka pendek.

\section{Tabel 5}

Hasil Pengukuran Cash Ratio (dalam jutaan rupiah)

\begin{tabular}{|c|c|c|c|c|}
\hline Tahun & Aktiva Lancar & Hutang Lancar & Hasil (\%) & Kriteria \\
\hline 2017 & 35.723 .971 & 427.720 .076 & $16,75 \%$ & Sehat \\
\hline 2018 & 53.374254 & 461.363 .532 & $11,56 \%$ & Sehat \\
\hline 2019 & 56.369 .680 & 513.578 .880 & $10,97 \%$ & Sehat \\
\hline
\end{tabular}

Sumber : Data diolah, 2021

Berdasarkan perhitungan cash ratio dapat disimpulkan bahwa kinerja keuangan PT Bank Central Asia Tbk yang diukur menggunakan rasio Cash Ratio (CR) masuk kriteria sehat, hasil tersebut sesuai standar kententuan yang telah ditetapkan BI melalui peraturan Nomor: 30/21/KEP/DER tanggal 30 April 1997 tentang Tata Cara Menilai Tingkat Kesehatan Bank mengenai kemapuan perusahaan dalam membayar kewajiban dalam jangka pendek. Pada periode 2018 - 2019 mengalami penurunan dalam dua periode, masih dalam kriteria sehat sesui dengan standar yang telah ditentukan.Penelitian ini sejalan dengan penelitian terdahulu yaitu pertama menurut Manimpurung et al., (2014) menyatakan bahwa PT Bank Rakyat Indonesia (Persero) Tbk menggunakan rasio Liquidity dengan analisis Cash Ratio (CR) dalam kriteria sehat. Kedua, menurut (Kevin, 2013) pada jurnal Analisis Laporan Keuangan dengan Menggunakan Metode CAMEL untuk Menilai Tingkat Kesehatan Perbankan Bank Umum Milik Pemerintah periode 2010-2011 menyatakan bahwa Perbankan Bank Umum Milik Pemerintah menggunakan rasio Liquidity dengan analisis Cash Ratio (CR) 
dalam kriteria sehat. Ketiga, menurut Saleo, (2015) dalam jurnal analisis tingkat kesehatan bank menyatakan bahwarasio CAR, KAP, DPN, ROA, BOPO, dan LDR berada dalam kondisi sehat sesuai ketentuan yang berlaku.

Berdasarkan perhitungan Capital Ratio PT Bank Central Asia Tbk Pada Periode 2017-2019 hasilnya dalam kriteria sehat, hasil perhitungan menujukan bahwa perusahaan mampu mencukupi permodalan yang penyediakan dana yang digunakan untuk mengatasi resiko pada perusahaan dalam periode berjalan. Earning Ratio masuk dalam kriteria sehat, hasil perhitungan ini menunjukan bahwa perusahan mengalami fluktuatif di setiap tahunnya. Kenaikan tersebut terjadi karena jumlah aktiva yang diperolah mengalami kenaikan yang lebih besar daripada laba sebelum pajak, dan mengalami penurunan karena laba sebelum pajak lebih besar daripada jumlah aktiva dan Beban Operasional Terhadap Pendapatan Operasional (BOPO) masuk dalam kriteria sehat dalam menutupi beban operasional kemungkinan yang terjadi pada perusahaan selama satu periode berjalan. Liquidity Ratio masuk dalam kriteria sehat, menunjukan bahwa perusahan mengalami fluktuatif di setiap tahunnya, meskipun mengalami penurunan masih dalam kriteria sehat, menujukaan mampu membayar kewajiban dalam jangka pendek dengan tepat waktu atau saat jatuh tempo.

\section{SIMPULAN DAN REKOMENDASI}

Hasil penelitian ini menyatakan bahwa analisis kinerja keuangan PT. Bank Central Asia,Tbk (BCA) yang dilakukan selama tahun 2017-2019 dengan menggunakan rasio CAR, ROA, BOPO dan CR menyatakan bahwa Bank BCA masuk dalam kategori/kriteria bank yang sehat. Dengan demikian maka yang seharusnya Bank BCA dapat mempertahankan bahkan meningkatkan kinerjanya baik dari segi aspek kinerja keuangan atau non keuangan agar nantinya Bank BCA tetap menjadi bank yang terdepan dalam industri ini, dan juga dapat menjadi bank peringkat pertama di Asia Tenggara.

\section{DAFTAR PUSTAKA}

Chandra, R., Mangantar, M., \& Oroh, S. G. (2016). Analisis Kinerja Keuangan PT Bank Syariah Mandiri Dan PT Bank Mandiri Tbk Dengan Menggunakan Metode Camel Analysis. Jurnal Berkala Imiah Efisiensi, 16(02), 2010-2016.

Citra, K., Merentek, C., Ekonomi, F., Manajemen, J., Sam, U., \& Manado, R. (2013). Analisis Kinerja Keuangan Antara Bank Negara Indonesia (Bni) Dan Bank Mandiri Menggunakan Metode Camel. Jurnal Emba, 1(3), 645-652. 
Kevin, J. (2013). Analisis Laporan Keuangan Dengan Menggunakan Metode Camel Untuk Menilai Tingkat Kesehatan Perbankan. Jurnal Emba, 1(3), 691-700.

Kurniawan, M. Z. (2017). Analisis Kinerja Keuangan Perusahaan Yang Terdaftar Di Bei Berbasis Rasio Likuiditas, Profitabilitas, Solvabilitas Dan Aktivitas. Akuntabilitas: Jurnal Ilmiah Ilmu-Ilmu Ekonomi, 10, 62-72.

Manimpurung, L., Nangoy, S. C., \& Mangantar, M. (2014). Analisis Kinerja Keuangan Dengan Menggunakan Camel Pada PT. Bank Rakyat Indonesia (Persero) Tbk. Jurnal Emba, 2(1), 404-410.

Saleo1, R. (2015). Analisis Tingkat Kesehatan Bank Dengan Menggunakan Metode Camel (Studi Kasus Pada PT. Bank Mandiri Tbk). Jurnal Emba, 5(2), 2143-2149.

Satria, I., \& Hatta, I. H. (2015). Pengaruh Kinerja Keuangan Terhadap Harga Saham 10 Bank Terkemuka di Indonesia. Jurnal Akuntansi, Xix(02), 179-191.

Wensen, N., Murni, S., \& Untu, V. (2017). Analisis Perbandingan Kinerja Keuangan Bank Mandiri (Persero) Tbk Dan Bank Central Asia (Persero) Tbk Periode Tahun 2011-2015. 5(2), 734-743.

Widyanto, E. A. (2012). Analisis Tingkat Kesehatan Dan Kinerja Keuangan Bank Dengan Menggunakan Metode Camel. Jurnal Eksis, 8(2), 2287-2296.

Yusra, M. (2019). Pengaruh Frekuensi Perdagangan , Trading Volume, Nilai Kapitalisasi Pasar, Harga Saham, Dan Trading Day Terhadap Return Saham Pada Perusahaan Kosmetik Dan Keperluan Rumah Tangga Di Bursa Efek Indonesia. Jurnal Akuntansi Dan Keuangan, 7, 65-74. 